\title{
Dynamic tax depreciation strategies
}

\author{
Anja De Waegenaere • Jacco L. Wielhouwer
}

(C) The Author(s) 2010. This article is published with open access at Springerlink.com

\begin{abstract}
The tax depreciation decision potentially has significant impact on the profitability of firms and projects. Indeed, the depreciation method chosen for tax purposes affects the timing of tax payments, and, as a consequence, it also affects the after-tax net present value of investment projects. Previous research focusses on the optimal choice of depreciation method under the assumption that the depreciation method has to be set ex ante and cannot be changed during the useful life of the asset. However, several countries allow changes of depreciation method under certain circumstances. This paper develops a dynamic programming approach to determine the firm's optimal choice with regard to the initial depreciation method, and whether changes of method are proposed in later periods.
\end{abstract}

Keywords Tax depreciation $\cdot$ Net present value $\cdot$ Dynamic programming

\section{Introduction}

To determine a firm's taxable income, cash flows are reduced with depreciation charges that reflect the decrease in economic value of the firm's assets. For practical purposes, a number of standardized depreciation methods have been designed. While certain

\footnotetext{
A. De Waegenaere $(\varangle)$

CentER for Economic Research, Department of Accounting and

Department of Econometrics and Operations Research, Tilburg University, P.O. Box 90153, 5000 LE Tilburg, The Netherlands

e-mail: a.m.b.DeWaegenaere@uvt.nl

J. L. Wielhouwer

Department of Accounting, Faculty of Economics, VU University Amsterdam, De Boelelaan 1105, 1081 HV Amsterdam, The Netherlands

e-mail: jwielhouwer@feweb.vu.nl
} 
countries mandate the use of a specific depreciation method, such as, e.g., Germany, other countries allow some flexibility. ${ }^{1}$ Examples of countries that allow flexibility include the US and the Netherlands. In the US, the tax authority allows firms to choose between the straight line depreciation method (SDM), which divides the asset value equally over the useful life of the asset, and a specified accelerated method, which assigns higher depreciation charges to earlier periods (see, e.g., U.S. Department of the Treasury 2008). In the Netherlands, the tax authority allows significant flexibility in the choice of depreciation scheme for start-up firms, and recently expanded this flexibility to stimulate investments in the current economic downturn. Specifically, it allows for any arbitrary accelerated depreciation scheme as long as the amount depreciated in a given year does not exceed $50 \%$ of the initial asset value. ${ }^{2}$

The choice of depreciation method potentially has important consequences. Indeed, since the depreciation method affects the timing of tax payments, it affects the net present value of the firm's after-tax revenues. Existing literature shows that tax depreciation can significantly affect the value of the firm and its investment behavior (see, e.g., Arkin and Slastnikov 2007; De Waegenaere et al. 2003; Sansing 1998; Wielhouwer et al. 2000).

The focus in our paper is on the choice of depreciation strategy that minimizes the expected present value of tax payments. The early literature on optimal tax depreciation (see, e.g., Davidson and Drake 1961, 1964; Roemmich et al. 1978; Wakeman 1980) assumes that the cash flow in every future period is high enough to cover the highest possible depreciation charge in that period. Then, it is optimal to choose the most accelerated depreciation method. The reason is that due to the time value of money, a dollar of tax paid this year decreases firm value to a larger extent than a dollar of tax paid in a later year. Therefore, it is optimal to depreciate as much as possible as early as possible, but never more than the cash flow in the corresponding period. A summary of the early literature can be found in Rueckle (1983). More recent literature extends the early work by allowing for uncertain future cash flows, reinvestments, and/or progressive tax structures, and shows that it is no longer necessarily the case that the most accelerated method is preferred (Berg et al. 2001; Berg and Moore 1989; De Waegenaere and Wielhouwer 2002; Dedner et al. 1980; Kromschroder 1984; Kunkel 1992; Wielhouwer et al. 2002).

The above described literature assumes that the depreciation method has to be set ex ante and cannot be changed during the lifetime of the asset. In countries where the tax authority allows some flexibility with regard to the choice of method, firms typically also have the option to request a change of method. In the Netherlands, for example, changes of depreciation method are typically allowed if they can be motivated on the basis of the economic depreciation in value of the asset. It is intuitively clear that the option to change depreciation method can reduce the expected present value of tax payments significantly. Ignoring this option value might imply that the firm underestimates the after-tax net present value (NPV) of investment projects by

\footnotetext{
1 At present, Germany temporarily allows using a more accelerated depreciation method for tax purposes due to the current financial crisis.

2 Source: http://www.kvk.nl/belastingen/.
} 
overestimating the expected tax payments (or by requiring a pre-tax rate of return that is too high). Our goal in this paper is therefore to determine the firm's optimal strategy with regard to the choice of depreciation method in the year of acquisition of an asset, and whether or not a change of method is proposed in later years. Since, as argued above, firms typically need to have an accurate motivation for a proposed change, we consider a model where there exists a positive probability that the tax authority will not accept the proposal. ${ }^{3}$ We allow this probability to depend on whether changes were proposed in earlier periods, and whether they were accepted.

We formulate the firm's decision problem as a dynamic optimization problem, and determine recursive relationships for the corresponding value functions. Then, we use these recursive relationships to investigate the effect of discounting (i.e., the time value of money) on the optimal depreciation strategy. We show that, as in the static setting considered in Berg et al. (2001), stronger discounting (i.e., a lower discount factor) works in favor of more accelerated methods. We then first numerically illustrate the basic tradeoffs that occur in settings without carry over of losses. We show that, even when changes are not accepted with certainty, it may be optimal for the firm to start off with a method that is suboptimal if future changes are not allowed, and propose a change later on. We find that the value of the option to change depreciation method (in terms of percentage reduction in expected discounted tax payments) can be significant, and depends on the discount factor, the cash flow patterns, and the probability that proposed changes are accepted.

Next, we extend our model to investigate the effect of the possibility to carry over losses to future periods on the value of the option to change depreciation method. It is well-known that the option to carry over losses decreases the present value of tax payments, and that if losses can compensate profits over the whole depreciable life of the asset, it is always optimal to use the most accelerated method. However, when the number of years that losses can be carried forward is limited, it is not necessarily the case that the most accelerated method is optimal (see Berg et al. 2001). This suggests that the option to change depreciation method can also be valuable in these settings. We, therefore, extend our model to include the possibility of carry over of losses, and derive the corresponding recursive relationship for the value function. We then use this recursive relationship to numerically illustrate the effect of carry over possibilities on the value of the option to change depreciation method. We find that carry over possibilities can increase the value of the option to change depreciation method compared to settings where carry over of losses is not allowed. This occurs because allowing carry forward may make it optimal to exercise the valuable option earlier.

The paper is organized as follows. Section 2 presents the model and the optimization problem. Section 3 reformulates the problem as a dynamic optimization problem. Section 4 deals with the effect of discounting on the optimal solution. Section 5 gives a numerical analysis. In Sect. 6 we show how the model can be extended to include carry forward of losses, and provide a numerical illustration of the effect of the option

\footnotetext{
3 IRS Publication 946 states: "Generally, you must get IRS approval to change your method of accounting. You generally must file Form 3115, Application for Change in Accounting Method, to request a change in your method of accounting for depreciation".
} 
to change depreciation method in this setting. Section 7 concludes. All proofs are deferred to the Appendix.

\section{The model}

A firm has an asset of value $D_{0}$ at time 0 , which can be depreciated for tax purposes over a maximum of $N$ periods. ${ }^{4}$ The depreciation charge in period $i$ reflects the reported decrease in value of the asset during that period. We formally distinguish a depreciation method and a depreciation scheme.

\section{Definition 1}

- A depreciation scheme for an asset of value $D_{0}$ consists of a vector $\bar{d}=$ $\left(d_{1}, \ldots, d_{N}\right) \in \mathbb{R}_{+}^{N}$ for some $N$ that satisfies

$$
\sum_{i=1}^{N} d_{i}=D_{0}
$$

- A depreciation method $M$ is represented by a function $f_{M}(\cdot, \cdot): \mathbb{N} \times \mathbb{N} \rightarrow[0,1]$ that satisfies

$$
\sum_{i=1}^{N} f_{M}(i, N)=1, \quad \text { for all } N
$$

When depreciation method $M$ is used throughout the depreciable life of an asset with initial value $D_{0}$, the corresponding depreciation scheme is given by

$$
d_{i}=f_{M}(i, N) \cdot D_{0}, \quad \text { for all } i=1, \ldots, N .
$$

In this paper, we focus on depreciation schemes that result from either using a particular depreciation method throughout the useful life of the asset, or from using a combination of depreciation methods. An example of a commonly used depreciation method is the straight line depreciation method (SDM), which divides the depreciation charges equally over the depreciable life of the asset, i.e.,

$$
f_{\mathrm{SDM}}(i, N)=\frac{1}{N}, \quad \text { for } i=1, \ldots, N \text {. }
$$

In contrast, the sum of the years' digits method (SYD) is an accelerated method in the sense that the depreciation charges decrease over time. Specifically,

$$
f_{\mathrm{SYD}}(i, N)=\frac{2(N-i+1)}{N(N+1)}, \quad \text { for } i=1, \ldots, N \text {. }
$$

\footnotetext{
${ }^{4}$ In case the salvage value of the asset is positive at the end of period $N, D_{0}$ represents the initial value reduced with the salvage value. For simplicity, however, we refer to $D_{0}$ as the initial value of the asset.
} 
Another example of an accelerated method is the double declining balance method (DDB). Under this method, a constant fraction of the residual tax base is depreciated in each year, where the residual tax base is equal to the original asset value reduced with prior depreciation charges. Because the fraction is twice the fraction under SDM, i.e., $\frac{2}{N}$, the method requires a depreciable lifetime of $N \geq 2$ periods, and the corresponding depreciation fractions (as fraction of the original asset value) are given by:

$$
\begin{aligned}
f_{\mathrm{DDB}}(i, N) & =\frac{2}{N}, & & \text { for } i=1, \\
& =\frac{2}{N}\left(1-\frac{2}{N}\right)^{i-1}, & & \text { for } i=2, \ldots, N-1, \\
& =\left(1-\frac{2}{N}\right)^{N-1}, & & \text { for } i=N .
\end{aligned}
$$

Finally, our model allows for depreciation methods under which the tax base of the asset is reduced to zero before the end of the economic life of the asset, i.e., where $f_{M}(i, N)=0$ for $i=j+1, \ldots, N$, for some $j<N$. An example of such a method is an immediate write-off, which is represented by:

$$
\begin{aligned}
f_{I}(i, N) & =1, \quad \text { for } i=1, \\
& =0, \quad \text { for } i=2, \ldots, N .
\end{aligned}
$$

As taxable income equals cash flow minus depreciation charges, the choice of depreciation scheme potentially has important consequences for tax payments. We consider a firm that wants to determine the depreciation strategy that maximizes the expected present value of future after-tax cash flows. For expositional purposes, we first abstract from carry over possibilities (compensating taxable profits with losses in earlier years, or losses with profits in earlier years). In Sect. 6, we show how the model can be extended to include carry forward of losses. ${ }^{5}$

If the cash flow in a given year exceeds the depreciation charge for that year, so that taxable income is positive, then taxes are paid on the difference between the cash flow and the depreciation charge. If the cash flow is lower than the depreciation charge, taxable income is negative, and no taxes are paid. Now let $\alpha^{(i)}=\frac{1}{\left(1+r^{(i)}\right)^{i}}$, where $r^{(i)}$ denotes the net rate of return required by shareholders. Then, the expected present value of future after-tax cash flows is given by:

$$
\sum_{i=1}^{N} \alpha^{(i)} E\left[C_{i}-\tau\left(C_{i}-d_{i}\right)^{+}\right]
$$

where $C_{i}$ denotes the random cash flow in year $i, d_{i}$ denotes the depreciation charge in year $i,\left(C_{i}-d_{i}\right)^{+}=\max \left\{C_{i}-d_{i}, 0\right\}$, and $\tau \in(0,1)$ denotes the tax rate. Clearly, maximizing the expected present value of after-tax cash flows is equivalent to

\footnotetext{
5 Earlier research (e.g. Berg et al. 2001) shows that, as long as the number of years that losses can be carried forward is limited, carry over possibilities do not significantly affect the qualitative results, although quantitative results may indeed change. In Sect. 6 we show that limited carry over possibilities can increase the value of the option to change depreciation method.
} 
minimizing the expected present value of future tax payments, which is given by:

$$
\tau \sum_{i=1}^{N} \alpha^{(i)} E\left[\left(C_{i}-d_{i}\right)^{+}\right]
$$

The existing literature focuses on the choice of depreciation method that minimizes (6) over a given set of acceptable depreciation methods, under the assumption that the depreciation method is chosen at date zero, and never changed afterwards. As stated in Sect. 1, however, firms typically have the possibility to propose a change of depreciation method in later periods. This implies that, in addition to choosing the initial depreciation method, the firm has to decide whether or not a change is proposed at the beginning of periods $i=2, \ldots, N$. Our goal in this paper is to determine the firm's optimal strategy with regard to the choice of depreciation method, and whether or not changes are proposed. ${ }^{6}$ According to common practice, we consider a setting where there are two acceptable depreciation methods, $A$ and $B$, e.g., an accelerated method and the straight line method, and we use the following notation:

$$
\begin{aligned}
& M^{c}=B \text {, if } M=A, \\
& =A, \text { if } M=B \text {. }
\end{aligned}
$$

With two methods and a possible change in each period, there are at most $2^{N-1}$ possible depreciation schemes. When there is no uncertainty regarding whether a proposal to change will be accepted, the firm's decision problem amounts to choosing the depreciation method that minimizes (6) among a subset of these $2^{N-1}$ depreciation schemes. The subset is determined by the tax authority's policy with regard to acceptance of changes. This is illustrated in the following example.

Example 1 Suppose that the tax authority accepts the first proposal to change method, and rejects all subsequent proposals. Then, there are $2 N$ possible depreciation schemes, resulting from using depreciation method $M \in\{A, B\}$ in periods $i=1, \ldots, k$, and method $M^{c}$ in periods $i=k+1, \ldots, N$, for $k=1, \ldots, N$. The corresponding depreciation charges are given by:

$$
\begin{aligned}
d_{i} & =f_{M}(i, N) D_{0}, & & i=1, \ldots, k, \\
& =f_{M^{c}}(i-k, N-k) D_{k}, & i & =k+1, \ldots, N,
\end{aligned}
$$

where $D_{0}$ denotes the initial asset value, and $D_{k}$ denotes the residual tax base at the start of period $k+1$, i.e., the initial asset value reduced with prior depreciation charges.

In this paper, however, we consider a setting where there is uncertainty as to whether a proposal will be accepted. As argued in Sect. 1, changes generally must be motivated

\footnotetext{
${ }^{6}$ Note that when at least one acceptable depreciation method reduces the tax base of the asset to zero in strictly less than $N$ periods, as is the case for example for an immediate write-off, the firm can to some extent affect the number of years over which the value of the asset is depreciated for tax purposes through a choice/change of depreciation method.
} 
on the basis of the economic decrease in value of the asset. This implies that the tax authority may refuse a change if it believes that the change is not well-motivated. In addition, the probability that a proposal to change will be accepted in a given period may also depend on whether the tax report is audited, and whether changes were proposed/accepted in prior periods. The fact that proposals may not be accepted implies that the firm optimally conditions its decision to propose a change on whether or not changes were proposed in prior periods and whether they were accepted. The objective of the firm then is to minimize the sum of the expected discounted tax payments through the following decision variables:

(i) the choice of the initial depreciation method $M$, and

(ii) the choice whether or not to propose a change in period $i$, depending on whether or not changes were proposed in prior periods and whether they were accepted.

Now let, for any given period $i$, a decision node $j$ represent one possible scenario with respect to whether changes were proposed in prior periods, and whether they were accepted. Since in each period either no change is proposed, a change is proposed, but not accepted, or a change is proposed and accepted, there are $3^{i-2}$ decision nodes in period $i$. We, therefore, introduce the decision variables:

$$
M \in\{A, B\}=\text { the initial depreciation method, }
$$

and, for every $i=2, \ldots, N$, and $j=1, \ldots, 3^{i-2}$,

$$
\begin{aligned}
\xi_{i, j} & =0, \text { if no change is proposed in period } i, \text { decision node } j \\
& =1, \text { if a change is proposed in period } i, \text { decision node } j
\end{aligned}
$$

and the random variables:

$$
\begin{aligned}
\phi_{i, j} & =0, \quad \text { if } \xi_{i, j}=0 ; \\
& =0, \quad \text { if } \xi_{i, j}=1, \text { and the proposed change is rejected; } \\
& =1, \quad \text { if } \xi_{i, j}=1, \text { and the proposed change is accepted. }
\end{aligned}
$$

We are now ready to formulate the optimization problem. First, it is clear that if the firm's decision in period $i$ depends on whether changes were proposed and/or accepted in prior periods, uncertainty regarding acceptance of proposals implies that the depreciation charge that will be applied in a given period, as well as whether a change will be proposed are random variables that depend on the initial choice $M$ and the change strategy $\xi$. Specifically, for any given $(M, \xi)$, we denote

- $\bar{d}_{i}(M, \xi)$ for the random variable that yields the depreciation charge in period $i$, for $i=1, \ldots, N$;

- $\bar{\xi}_{i}(M, \xi)$ for the random variable that equals 1 if a change is proposed at the beginning of period $i$, and 0 otherwise, for $i=2, \ldots, N$.

Then, the amount of tax to be paid at the end of period $i$ equals $\tau\left(C_{i}-\bar{d}_{i}(M, \xi)\right)^{+}$. The optimal initial choice $M$ and the optimal change strategy $\xi$ therefore solve the following optimization problem: 


$$
\begin{array}{ll}
\min & \tau \sum_{i=1}^{N} \alpha^{(i)} E\left[\left(C_{i}-\bar{d}_{i}(M, \xi)\right)^{+}\right] \\
\text {s.t. } & \left\{\begin{array}{l}
M \in\{A, B\} \\
\xi_{i} \in\{0,1\}^{i-2}, \quad \text { for } i=2, \ldots, N .
\end{array}\right.
\end{array}
$$

Since the optimal depreciation strategy is not affected by the tax rate, we divide the objective function by $\tau$, so that the expected present value of the tax base is minimized.

To solve the optimization problem, the probability distribution of $\bar{d}_{i}(M, \xi)$ for $i=1, \ldots, N$ as well as the probability distribution of $\bar{\xi}_{i}(M, \xi)$ for $i=2, \ldots, N$, need to be determined for any given change strategy $\xi$, and any initial method $M$. These probability distributions depend on how the probability of acceptance of a proposal depends on whether proposals were made in earlier periods, and whether they were accepted.

The following proposition considers the case where at most one proposal will be accepted. First, we introduce some notation. Without loss of generality, we let decision node $(i, 1)$ represent the unique node in period $i$ in which no changes were proposed in prior periods. Moreover, let $d_{(M, k)}, k=1, \ldots, N$, represent the depreciation scheme that results from using method $M \in\{A, B\}$ in periods $i=1, \ldots, k$, and using method $M^{c}$ in periods $k+1, \ldots, N$.

Proposition 1 Consider a setting where, as long as no prior proposal has been accepted, the probability that a proposal will be accepted is constant and equal to $p$. As soon as a prior proposal has been accepted, all future proposals will be rejected. Then, under the optimal strategy, the probability distribution of the resulting depreciation scheme is given by:

$$
\begin{aligned}
P\left(\bar{d}(M, \xi)=d_{(M, k)}\right) & =\xi_{k+1,1} \cdot p \cdot(1-p)^{\sum_{j=2}^{k} \xi_{j, 1}}, & & k=1, \ldots, N-1, \\
& =(1-p)^{\sum_{j=2}^{N} \xi_{j, 1}}, & & k=N,
\end{aligned}
$$

and the probability that a change is proposed at the beginning of period $i$ is given by:

$$
P\left(\bar{\xi}_{i}(M, \xi)=1\right)=\xi_{i, 1} \cdot(1-p)^{\sum_{j=2}^{i-1} \xi_{j, 1}} .
$$

The above proposition shows that in the case where the probability of acceptance is constant as long as no prior change has been accepted and drops to zero as soon as a change has been accepted, the number of decision variables in optimization problem (6) reduces from $1+\sum_{i=2}^{N} 3^{i-2}$ to $N$. The firm's optimal strategy can then be found by plugging in (10) and (11) in the objective function of optimization problem (9), and determining the optimal value over all $M \in\{A, B\}$, and $\xi_{i, 1} \in\{0,1\}$ for $i=2, \ldots, N$. We illustrate this in the following example.

Example 2 Consider an asset with a depreciable lifetime of 5 years, i.e., $N=5$, and an initial value of $D_{0}=5$. The firm initially has the option to choose either SDM, or SYD, and can propose a change of method in later periods. As long as no prior 


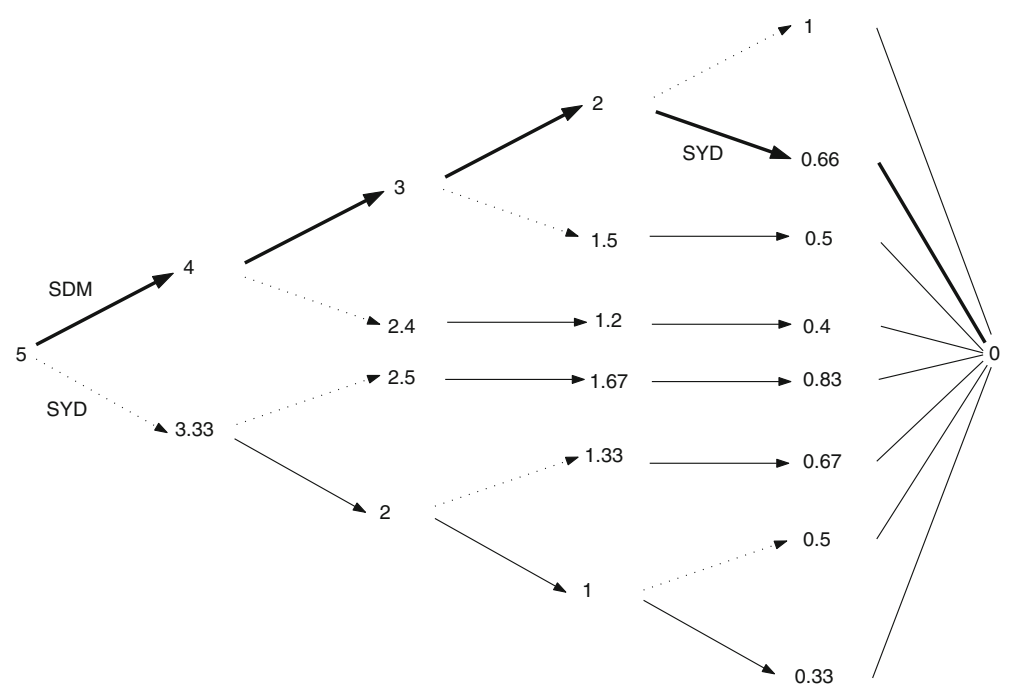

Fig. 1 Decision tree: in every decision node, the upper (lower) arrow corresponds to the use of SDM (SYD); a straight arrow indicates that a change is no longer possible. In each node, the optimal (suboptimal) choice is indicated with a solid (dotted) arrow. The optimal trajectory is indicated with bold arrows. The values at the nodes indicate the residual tax base in that node

proposal has been accepted, the probability that a proposal will be accepted is constant and equal to $p=0.9$. As soon as a prior proposal has been accepted, all future proposals will be rejected. The decision tree is displayed in Fig. 1.

The only possible depreciation schemes are $d_{(M, k)}$, for $M \in\{\mathrm{SDM}, \mathrm{SYD}\}$ and $k=1, \ldots, N$, with depreciation charges given by:

$$
\begin{aligned}
d_{(M, k), i} & =f_{M}(i, 5) \cdot 5, & i & =1, \ldots, k, \\
& =f_{M^{c}}(i-k, 5-k)\left(5-\sum_{j=1}^{k} d_{(M, k), j}\right), & i & =k+1, \ldots, 5 .
\end{aligned}
$$

Now, we let $\alpha^{(i)}=\alpha^{i}$ with $\alpha=0.95$. The cash flow in period $i=1, \ldots, 5$ is normally distributed with mean $\mu_{i}$ and standard deviation $\sigma_{i}$ as given in the following table:

\begin{tabular}{|c|ccccc|}
\hline Period $i$ & 1 & 2 & 3 & 4 & 5 \\
\hline$\mu_{i}$ & 1.5 & 1 & 2 & 3 & 0.5 \\
$\sigma_{i}$ & 1 & 2 & 2 & 2 & 3 \\
\hline
\end{tabular}

Without the possibility to change depreciation method, the expected discounted tax payments using SDM and SYD are 5.36 and 5.34, respectively, so that SYD is the preferable method. Allowing for the possibility to change, however, implies that it is optimal to start with SDM, and propose a change of method in period 4. This strategy reduces the expected present value of tax payments to 5.26. 
In the setting described in Proposition 1, it is possible to determine the probability distribution of the depreciation charges in each period for any given strategy. In more general cases, however, this becomes complicated. Then, an efficient method to solve optimization problem (9) is dynamic programming. In Sect. 3, we therefore develop a dynamic optimization approach to determine the firm's optimal strategy.

\section{Dynamic optimization}

The basic idea of the dynamic optimization approach is to recursively determine the value function in period $i$, for $i=N, N-1, \ldots, 1$. This value function yields the minimal expected present value of the sum of tax payments in periods $i, \ldots, N$, for any possible value of the state variables at the beginning of period $i$. Given the analysis in the previous section, we let the state variables in period $i$ be given by $s_{i}=\left(M_{1}, \bar{\xi}_{i-1}, \bar{\phi}_{i-1}\right)$, where:

- $M_{1} \in\{A, B\}$ denotes the method that is used in period 1;

- $\bar{\xi}_{i-1}=\left(\xi_{1}, \ldots, \xi_{i-1}\right) \in\{0,1\}^{i-1}$ denotes whether a change was proposed at the beginning of periods $j=1, \ldots, i-1$;

- $\bar{\phi}_{i-1}=\left(\phi_{1}, \ldots, \phi_{i-1}\right) \in\{0,1\}^{i-1}$ denotes whether a change was accepted in periods $j=1, \ldots, i-1$.

To determine the optimal decision at the start of period $i$ for any given value of $s_{i}$, the following has to be known:

- the expected tax payments in period $i$, as a function of $s_{i}$ and the decision at the beginning of period $i$;

- the probability distribution of $s_{i+1}$, as a function of $s_{i}$ and the decision at the beginning of period $i$.

It therefore remains to: (i) specify the probability distribution of the state variables, and, (ii) show that $\left(M_{1}, \bar{\xi}_{i-1}, \bar{\phi}_{i-1}\right)$ is sufficient to determine the expected tax payments in period $i$. This will be dealt with in Sects. 3.1 and 3.2, respectively. Section 3.3 presents the recursive evaluation of the value functions.

\subsection{Probability distribution of state variables}

In period $i=1$, there is no proposal to change, and so $\xi_{1}=\phi_{1}=0$. Therefore, $s_{2}=\left(M_{1}, 0,0\right)$ with probability 1 . For periods $i=2, \ldots, N$, we let:

$$
p_{i}\left(\bar{\xi}_{i-1}, \bar{\phi}_{i-1}\right)=P\left(\phi_{i}=1 \mid \xi_{i}=1 ; \xi_{2}, \ldots, \xi_{i-1} ; \phi_{2}, \ldots, \phi_{i-1}\right)
$$

denote the probability that a proposed change will be accepted at the beginning of period $i$, as a function of whether or not changes were proposed in periods prior to period $i$ (i.e., $\xi_{2}, \ldots, \xi_{i-1}$ ), and whether or not they were accepted (i.e., $\phi_{2}, \ldots, \phi_{i-1}$ ).

Now, given state variables $s_{i}=\left(M_{1}, \bar{\xi}_{i-1}, \bar{\phi}_{i-1}\right)$ at the beginning of period $i$, the probability distribution of the state variables in period $i+1$ depends on whether a change is proposed at the beginning of period $i$. Specifically, 
- when no change is proposed, $\xi_{i}=\phi_{i}=0$, and so $s_{i+1}=\left(M_{1},\left(\bar{\xi}_{i-1}, 0\right),\left(\bar{\phi}_{i-1}, 0\right)\right)$ with probability 1 ;

- when a change is proposed, then $\xi_{i}=1$, and two cases are possible: with probability $p_{i}\left(\bar{\xi}_{i-1}, \bar{\phi}_{i-1}\right)$ the change is accepted $\left(\phi_{i}=1\right)$, so that $s_{i+1}=$ $\left(M_{1},\left(\bar{\xi}_{i-1}, 1\right),\left(\bar{\phi}_{i-1}, 1\right)\right)$; with probability $\left(1-p_{i}\left(\bar{\xi}_{i-1}, \bar{\phi}_{i-1}\right)\right)$ it is not accepted $\left(\phi_{i}=0\right)$, so that $s_{i+1}=\left(M_{1},\left(\bar{\xi}_{i-1}, 1\right),\left(\bar{\phi}_{i-1}, 0\right)\right)$.

\subsection{Expected tax payments}

The following lemma shows that the depreciation charge to be used in period $i$ when method $M$ is used in that period depends only on: the period $i$, the residual tax base at the beginning of period $i$, and the last period before period $i$ in which method $M$ was not used, which we denote by $j-1$.

Lemma 1 Suppose method $M$ is used in periods $k=j, \ldots, i-1$, method $M^{c}$ is used in period $j-1$, and the residual tax base at the beginning of period $i$ equals $D$. Then, there exists a $q_{i, j, N} \in[0,1]$ such that the depreciation charge to be used in period $i$ if method $M$ is used is given by:

$$
\begin{aligned}
d_{i} & =\frac{f_{M}(i-j+1, N-j+1)}{1-\sum_{k=1}^{i-j} f_{M}(k, N-j+1)} D \\
& =q_{i, j, N} \cdot D
\end{aligned}
$$

Moreover, $q_{N, \cdot, N}=1$.

The above lemma shows that, for any given depreciation method, the fraction of the residual tax base to be depreciated in period $i$ is a function of the current period $i$, the useful life of the asset $N$, and the last period before period $i$ in which the method was not used (period $j-1$ ). For example, it is easily verified that in case of SDM, SYD, and DDB, as defined in (3), (4), and (5), respectively, the fractions $q_{i, j, N}$ are given by:

$$
\begin{array}{rlrl}
q_{i, j, N, \mathrm{SDM}} & =\frac{1}{N+1-i}, & & \text { for } i=1, \ldots, N, \\
q_{i, j, N, \mathrm{SYD}}=\frac{2}{N+2-i}, & & \text { for } i=1, \ldots, N, \\
q_{i, j, N, \mathrm{DDB}}=\frac{2}{N-j+1}, & & \text { for } i=1, \ldots, N-1, \\
& =1, & & \text { for } i=N .
\end{array}
$$

Note that in case of SDM and SYD, $q_{i, j, N}$ is independent of $j$. For notational convenience, we restrict to depreciation methods for which the fraction of the residual tax base to be depreciated in a given period $i$ is independent of $j .{ }^{7}$ Moreover, since the maximum depreciable lifetime of the asset $N$ is given and fixed, we omit the index $N$,

\footnotetext{
7 Allowing the fractions to depend on $j$ increases notational complexity, but it does not otherwise affect the results.
} 
and we denote $q_{i, M}:=q_{i, \cdot, N}$ for the fraction of the residual tax base to be depreciated in period $i$ if method $M$ is used. This yields the following lemma.

Lemma 2 For any given residual tax base $D$ at the beginning of period $i$, the expected tax to be paid in period $i$ if method $M$ is used in period $i$, is given by:

$$
\operatorname{Tax}(i, M, D)=\int_{q_{i, M} \cdot D}^{\infty}\left(1-F_{i}(x)\right) \mathrm{d} x
$$

where $F_{i}(\cdot)$ denotes the distribution function of the cash flow in period $i$.

It now remains to show that $\left(M_{1}, \bar{\xi}_{i-1}, \bar{\phi}_{i-1}\right)$ is sufficient to determine the expected tax payments in period $i$ for any possible decision. First, since a change of method only occurs when $\xi_{i}=1$ and $\phi_{i}=1$, it follows immediately that the method $M_{i}$ used in period $i$ is determined recursively as follows:

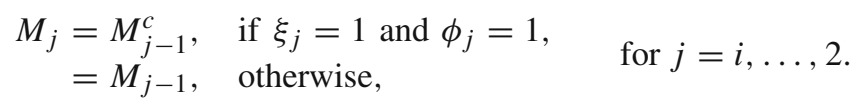

and, given Lemma 1 , it follows that the residual tax base $D_{i-1}$ at the beginning of period $i$ is determined recursively by:

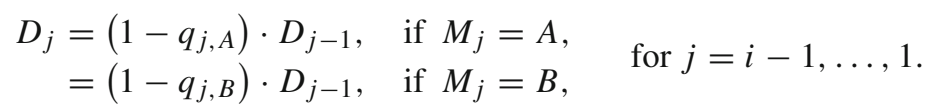

where $D_{0}$ denotes the initial asset value (initial depreciable amount).

Now let $\left(M_{1}, \bar{\xi}_{i-1}, \bar{\phi}_{i-1}\right)$ be a decision node in period $i$. Then,

- if no change is proposed at the beginning of period $i$, the expected tax payments in period $i$ are given by $\operatorname{Tax}\left(i, M_{i-1}, D_{i-1}\right)$;

- if a change is proposed at the beginning of period $i$, then the expected tax payments in period $i$ are given by $p_{i}\left(\bar{\xi}_{i-1}, \bar{\phi}_{i-1}\right) \cdot \operatorname{Tax}\left(i, M_{i-1}^{c}, D_{i-1}\right)+\left(1-p_{i}\left(\bar{\xi}_{i-1}, \bar{\phi}_{i-1}\right)\right)$. $\operatorname{Tax}\left(i, M_{i-1}, D_{i-1}\right)$.

Therefore, expected tax payments in period $i$ can be determined from $\left(M_{1}, \bar{\xi}_{i-1}\right.$, $\left.\bar{\phi}_{i-1}\right)$, where $M_{i-1}$ and $D_{i-1}$ follow from (13) and (14).

\subsection{Recursive evaluation}

While $\left(M_{1}, \bar{\xi}_{i-1}, \bar{\phi}_{i-1}\right)$ yields sufficient information to determine the optimal decision in period $i$, it follows from Lemma 2, (13) and (14), that it is convenient to use the following, equivalent, set of state variables $\left(M, D, \bar{\xi}_{i-1}, \bar{\phi}_{i-1}\right)$, where $M$ denotes the method that was used in period $i-1$, and $D$ denotes the residual tax base at the end of period $i-1$.

We now define the value functions as follows. The function

$$
V_{i}\left(M, D, \bar{\xi}_{i-1}, \bar{\phi}_{i-1}\right):\{A, B\} \times \mathbb{R} \times\{0,1\}^{i-1} \times\{0,1\}^{i-1} \rightarrow \mathbb{R},
$$


for $i=2, \ldots, N$, yields the minimal expected present value of future tax payments for periods $i, \ldots, N$, given $\left(M, D, \bar{\xi}_{i-1}, \bar{\phi}_{i-1}\right)$. The function

$$
V_{1}\left(D_{0}\right): \mathbb{R} \rightarrow \mathbb{R}
$$

yields the minimal expected present value of future tax payments for all periods, as a function of the initial value of the asset $D_{0}$. The following proposition provides a recursive relationship for the value functions, where

$$
\alpha_{i}:=\alpha^{(i)} / \alpha^{(i-1)} \in[0,1]
$$

denotes the value at date $i-1$ of one unit at date $i$.

Proposition 2 Let:

$$
V_{N+1}(\cdot, \cdot, \cdot, \cdot):=0
$$

Then, for all $i=2, \ldots, N$,

$$
\begin{aligned}
V_{i}\left(M, D, \bar{\xi}_{i-1}, \bar{\phi}_{i-1}\right) \\
=\min \left\{\begin{array}{c}
\operatorname{Tax}(i, M, D)+\alpha_{i} \cdot V_{i+1}\left(M,\left(1-q_{i, M}\right) D,\left(\bar{\xi}_{i-1}, 0\right),\left(\bar{\phi}_{i-1}, 0\right)\right), \\
p_{i}\left(\bar{\xi}_{i-1}, \bar{\phi}_{i-1}\right) \cdot\left[\operatorname{Tax}\left(i, M^{c}, D\right)+\alpha_{i} \cdot V_{i+1}\left(M^{c},\left(1-q_{i, M^{c}}\right) D,\left(\bar{\xi}_{i-1}, 1\right),\right.\right. \\
\left.\left.\left(\bar{\phi}_{i-1}, 1\right)\right)\right] \\
+\left(1-p_{i}\left(\bar{\xi}_{i-1}, \bar{\phi}_{i-1}\right)\right) \cdot\left[\operatorname{Tax}(i, M, D)+\alpha_{i} V_{i+1}\left(M,\left(1-q_{i, M}\right) D,\right.\right. \\
\left.\left.\left(\bar{\xi}_{i-1}, 1\right),\left(\bar{\phi}_{i-1}, 0\right)\right)\right]
\end{array}\right.
\end{aligned}
$$

and

$$
V_{1}(D)=\min _{M \in\{A, B\}}\left\{\operatorname{Tax}(1, M, D)+\alpha_{1} \cdot V_{2}\left(M,\left(1-q_{1, M}\right) D, 0,0\right)\right\} .
$$

Note that the choice of $\xi_{i}$ not only affects the depreciation method and the residual tax base in the next period, but also the probability that a future change will be accepted. When no change is proposed in period $i$, the probability of acceptance in the next period is given by $p_{i+1}\left(\left(\bar{\xi}_{i-1}, 0\right),\left(\bar{\phi}_{i-1}, 0\right)\right)$; when a change is proposed and accepted, it is given by $p_{i+1}\left(\left(\bar{\xi}_{i-1}, 1\right),\left(\bar{\phi}_{i-1}, 1\right)\right)$; when a change is proposed, but not accepted, it is given by $p_{i+1}\left(\left(\bar{\xi}_{i-1}, 1\right),\left(\bar{\phi}_{i-1}, 0\right)\right)$.

The following corollary follows immediately from Proposition 2.

Corollary 1 It holds that:

i) It is optimal to choose method $M$ in period 1 iff

$$
\begin{aligned}
& \operatorname{Tax}(1, M, D)+\alpha_{1} \cdot V_{2}\left(M,\left(1-q_{1, M}\right) D, 0,0\right) \\
& \quad \leq \operatorname{Tax}\left(1, M^{c}, D\right)+\alpha_{1} \cdot V_{2}\left(M^{c},\left(1-q_{1, M^{c}}\right) D, 0,0\right) .
\end{aligned}
$$


ii) In periods $i=2, \ldots, N$, a change should be proposed iff

$$
\begin{aligned}
& p_{i}\left(\bar{\xi}_{i-1}, \bar{\phi}_{i-1}\right) \cdot\left[\operatorname{Tax}(i, M, D)-\operatorname{Tax}\left(i, M^{c}, D\right)\right] \\
& \quad+\alpha_{i} \cdot S_{i+1}\left(M, D, \bar{\xi}_{i-1}, \bar{\phi}_{i-1}\right) \geq 0
\end{aligned}
$$

where

$$
\begin{aligned}
& S_{i+1}\left(M, D, \bar{\xi}_{i-1}, \bar{\phi}_{i-1}\right)=V_{i+1}\left(M,\left(1-q_{i, M}\right) D,\left(\bar{\xi}_{i-1}, 0\right),\left(\bar{\phi}_{i-1}, 0\right)\right) \\
& \quad-p_{i}\left(\bar{\xi}_{i-1}, \bar{\phi}_{i-1}\right) \cdot V_{i+1}\left(M^{c},\left(1-q_{i, M^{c}}\right) D,\left(\bar{\xi}_{i-1}, 1\right),\left(\bar{\phi}_{i-1}, 1\right)\right) \\
& -\left(1-p_{i}\left(\bar{\xi}_{i-1}, \bar{\phi}_{i-1}\right)\right) \cdot V_{i+1}\left(M,\left(1-q_{i, M}\right) D,\left(\bar{\xi}_{i-1}, 1\right),\left(\bar{\phi}_{i-1}, 0\right)\right) .
\end{aligned}
$$

The above corollary shows that it is optimal to propose a change in period $i$ iff the expected benefit from the proposal is positive. This expected benefit consists of two parts: (i) the expected reduction in tax payments in period $i$, which is equal to $p_{i}\left(\bar{\xi}_{i-1}, \bar{\phi}_{i-1}\right) \cdot\left[\operatorname{Tax}(i, M, D)-\operatorname{Tax}\left(i, M^{c}, D\right)\right]$, and (ii) the present value of the expected reduction in tax payments in all future periods, which is given by $\alpha_{i} \cdot S_{i+1}\left(M, D, \bar{\xi}_{i-1}, \bar{\phi}_{i-1}\right)$. It is clear that the discount factor $\alpha_{i}$ can play a crucial role in whether or not it is optimal to propose a change. In Sect. 4, we investigate the effect of discounting on the optimal decision in each period.

\section{Effect of discounting}

Berg et al. (2001) consider the case where $\alpha^{(i)}=\alpha^{i}$, for all $i$, and where a change of method is never allowed. They then show that less discounting (a higher value of $\alpha$ ) works in favor of the least accelerated method. In our setting, however, a decision has to be made in every period. We allow the discount factor to be different for different periods, i.e., $\alpha^{(i)}=\alpha_{1} \cdot \alpha_{2} \cdots \cdots \alpha_{i} \neq \alpha^{i}$, and consider a method to be more accelerated in period $i$ if the depreciation charge in that period exceeds the depreciation charge of the alternative method.

We now characterize the effect of discounting on optimal depreciation method choice in settings where changes are allowed. First, it is clear that a proposal to change depreciation method in the last period has no effect, because the depreciation charge in the last period is always equal to the residual tax base. In the following proposition we show that for all periods $i=1, \ldots, N-1$, there exists a critical value of the discount factor $\widetilde{\alpha}_{i}$ such that the most (least) accelerated method is optimal if $\alpha_{i}<\widetilde{\alpha}_{i}$ $\left(\alpha_{i}>\widetilde{\alpha}_{i}\right)$.

Proposition 3 For any given period $i \in\{1, \ldots, N-1\}$, and state $\left(M, D, \bar{\xi}_{i-1}, \bar{\phi}_{i-1}\right)$, there exists a critical value $\tilde{\alpha}_{i} \leq 1$ such that the most (least) accelerated method in period $i$ is preferable if $\alpha_{i}<\tilde{\alpha}_{i}\left(\alpha_{i}>\tilde{\alpha}_{i}\right)$.

The intuition that more discounting works in favor of more accelerated methods is that these methods typically lower taxable income in earlier periods. 


\section{Numerical illustration}

In this section we illustrate the effect of the probability of acceptance and of the cash flow distributions on the optimal initial choice, the expected present value of tax payments, and the value of the option to change depreciation method. Throughout this section we consider a setting where:

- The acceptable depreciation methods are $S D M$ and $S Y D$, as defined in (12).

- The depreciable lifetime of the asset equals $N=10$, and the initial amount to depreciate equals $D_{0}=10$.

- The discount factor in period $i$ is given by $\alpha_{i}=\alpha=0.95$ for all $i$.

In Sect. 5.1 we consider given cash flow distributions, and investigate the effect of the probability of acceptance of a proposal to change depreciation method. In Sect. 5.2 we investigate the effect of the cash flow distributions.

\subsection{Effect of the probability of acceptance}

We consider settings where the probability of acceptance of a proposal to change depreciation method decreases with $v \cdot 100 \%$ after each accepted proposal. Then, for a given change strategy $\bar{\xi}$, the probability that a change proposed in period $i$ will be accepted is given by:

$$
\begin{aligned}
& p_{i}\left(\bar{\xi}_{i-1}, \bar{\phi}_{i-1}\right)=p, \quad \text { if } \bar{\xi}_{i-1}=\left(\xi_{1}, \ldots, \xi_{i-1}\right)=(0, \ldots, 0), \text { and } \\
& p_{i}\left(\bar{\xi}_{i-1}, \bar{\phi}_{i-1}\right)=(1-v)^{\sum_{k=1}^{i-1} \phi_{k}} p, \\
& \text { otherwise. }
\end{aligned}
$$

where $p$ denotes the probability of acceptance of the first proposal. We first illustrate the effect of $p$ in the case where $v=0$. Then, we investigate the effect of $v$ for given values of $p$.

In both cases, cash flows are normally distributed. The means and standard deviations of the cash flow distributions are given in the following table:

\begin{tabular}{|c|cccccccccc|}
\hline Period i & 1 & 2 & 3 & 4 & 5 & 6 & 7 & 8 & 9 & 10 \\
\hline$E\left[C_{i}\right]$ & 1 & 2 & 2 & 3 & 3 & 4 & 4 & 3 & 0 & 2 \\
$\sigma\left[C_{i}\right]$ & 2 & 2 & 2 & 2 & 2 & 2 & 2 & 2 & 2 & 2 \\
\hline
\end{tabular}

This reflects a setting where the variance is constant over the periods, but expected income generated by the asset grows in early periods, and starts to decrease as of period 8 . The expected revenue in the last period may include the salvage value of the asset at the end of its economic life.

When $v=0$, the probability of acceptance is independent of earlier decisions, so that:

$$
p_{i}\left(\bar{\xi}_{i-1}, \bar{\phi}_{i-1}\right)=p, \quad \text { for all } i=2, \ldots, 10
$$


The following table presents the minimum (over all possible change strategies) of the expected present value of tax payments when the method applied in the first period is SDM and SYD, respectively, for five different values of $p$. The optimal value is indicated in bold. The third column presents the option value expressed as percentage reduction in the expected present value of tax payments due to the possibility to change depreciation method, i.e., compared to the case where $p=0$.

\begin{tabular}{|c|ccc|}
\hline$p$ & SDM & SYD & Option value (\%) \\
\hline 0 & 14.28 & $\mathbf{1 4 . 1 0}$ & 0 \\
0.3 & $\mathbf{1 3 . 9 7}$ & 14.10 & 0.9 \\
0.5 & $\mathbf{1 3 . 9 2}$ & 14.09 & 1.3 \\
0.8 & $\mathbf{1 3 . 8 7}$ & 14.05 & 1.6 \\
1 & $\mathbf{1 3 . 8 5}$ & 14.03 & 1.8 \\
\hline
\end{tabular}

Without the possibility to change the depreciation method, i.e., when $p=0$, the expected discounted tax payments equal 14.28 for SDM, and 14.10 for SYD, so that SYD is the optimal method. In contrast, if changes are allowed with certainty, i.e., $p=1$, then it is optimal to start with SDM, and propose changes of depreciation method in later periods. Specifically, the optimal strategy would be to apply SDM at the beginning, switch to SYD in period 4, and change to SDM again in period 9. When the probability that a change will be accepted is relatively low (in this case $p<0.1155$ ), the expected benefit from being allowed to change depreciation method does not outweigh the loss in case an anticipated change is not accepted. Therefore, when $p$ is low, the firm does not anticipate changes and chooses the method that is optimal in case changes are not allowed. In contrast, when the probability of acceptance of a proposal to change method is sufficiently large (i.e., $p>0.1155$ ), it is optimal for the firm to start off with the method that is suboptimal if no change is allowed, and "bet" on acceptance of a change in a later period. Thus, the firm optimally starts with SDM, and later on proposes a change to SYD. The option to change depreciation method therefore is valuable whenever $p>0.1155$.

The above example shows that the more accelerated method is the optimal initial choice only when the probability that a change will be accepted is relatively low. We know from Proposition 9 that the choice between the accelerated and the straight line method can also significantly depend on the discount factor. In Fig. 2, we illustrate how the optimal initial choice between SDM and SYD depends on $\alpha$ and $p$. As expected, a stronger discounting effect, i.e., a lower discount factor increases the range of values of $p$ for which the accelerated method is optimal.

We now consider the case where $v>0$, so that there is an opportunity cost associated with proposing a change because it reduces the likelihood that a next proposal will be accepted. The following table presents the minimum over all possible change strategies of the expected present value of tax payments when the initial method is SDM and SYD, respectively, for different values of $v$ and $p$. 


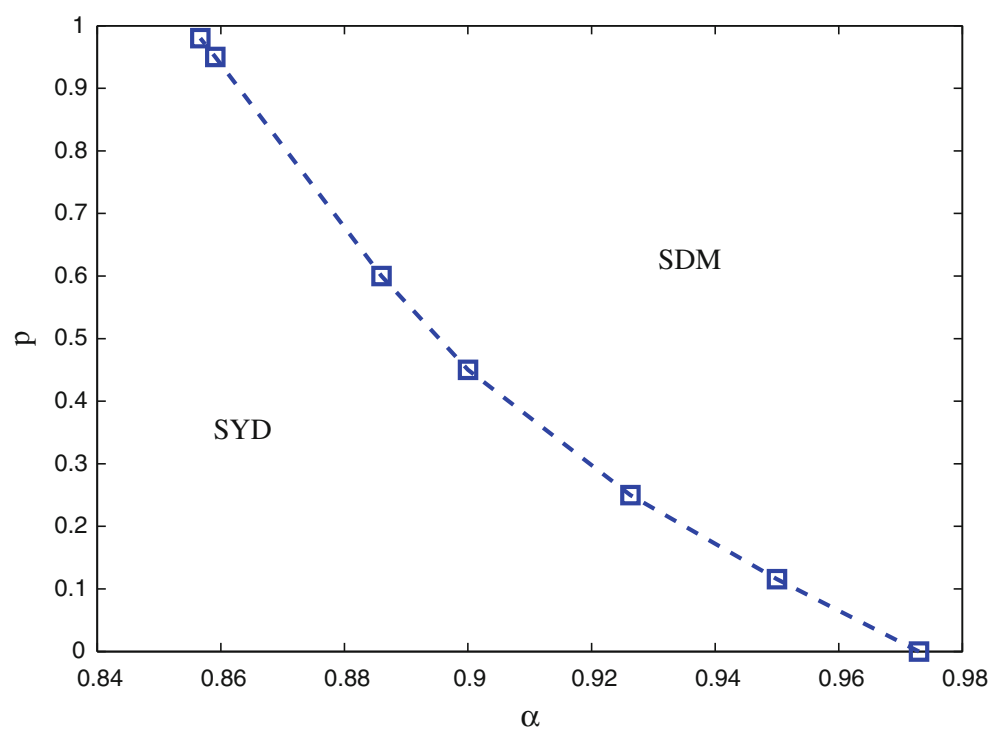

Fig. 2 The effect of $\alpha$ and $p$ on the optimal initial depreciation method choice: SDM or SYD

\begin{tabular}{|c|cc|cc|cc|cc|}
\hline & \multicolumn{2}{|c|}{$v=5 \%$} & \multicolumn{2}{c|}{$v=20 \%$} & \multicolumn{2}{c|}{$v=50 \%$} & \multicolumn{2}{c|}{$v=100 \%$} \\
\hline$p$ & SDM & SYD & SDM & SYD & SDM & SYD & SDM & SYD \\
\hline 0.5 & $\mathbf{1 3 . 9 2}$ & 14.09 & $\mathbf{1 3 . 9 3}$ & 14.09 & $\mathbf{1 3 . 9 3}$ & 14.09 & $\mathbf{1 3 . 9 4}$ & 14.09 \\
1 & $\mathbf{1 3 . 8 5}$ & 14.03 & $\mathbf{1 3 . 8 6}$ & 14.05 & $\mathbf{1 3 . 8 7}$ & 14.08 & $\mathbf{1 3 . 8 8}$ & 14.08 \\
\hline
\end{tabular}

Because the optimal strategy in case proposals are accepted with certainty (i.e., $p=1$ and $v=0$ ) involves multiple changes of depreciation method, a higher value of $v$ can affect the optimal strategy and the expected discounted tax payments, since it implies that the likelihood that the second proposal will be accepted is lower. In all the above cases, SDM is the optimal initial choice. The effect of decreasing probabilities is relatively small in this example since the second change is only proposed in period 9 , so that discounted benefits are relatively small.

\subsection{Effect of cash flow patterns}

In this section we numerically illustrate the effect of cash flow patterns on the optimal initial choice, the expected present value of tax payments, and the value of the option to change depreciation method. In order to investigate the effect of patterns in the expected value as well as in the variance of future cash flows, we distinguish scenarios with increasing, decreasing, and non-monotone patterns in expected cash flows, but with constant variance, as well as scenarios with increasing and decreasing patterns in variances, but constant expected cash flows. In each case, cash flows are normally distributed. 
We first investigate the effect of patterns in the expected future cash flows, in settings where the variance is constant over time, i.e., $\sigma_{i}=\sigma$ for all $i$. Specifically, we define the following four scenarios for the expected cash flows $\mu_{i}$, for period $i=1, \ldots, 10$ :

I: Increasing expected cash flows over time, with $\mu_{i}=0.5 \cdot i$;

II: decreasing expected cash flows over time, with $\mu_{i}=5.5-0.5 \cdot i$;

III: increasing and subsequently decreasing expected cash flows, with $\left\{\mu_{1}, \mu_{2}, \ldots\right.$, $\left.\mu_{10}\right\}=\{0,1,2.5,4,5,5,4,2.5,1,0\}$;

IV: decreasing and subsequently increasing expected cash flows, with $\left\{\mu_{1}, \mu_{2}, \ldots\right.$, $\left.\mu_{10}\right\}=\{5,4,2.5,1,0,0,1,2.5,4,5\}$.

In all four scenarios, the expected total cash flow over the economic life of the asset, i.e., $\sum_{i=1}^{10} \mu_{i}$, is equal to 25 . The following table presents the minimum over all possible change strategies of the expected present value of tax payments when the initial method is $S D M$ and $S Y D$, respectively. We consider settings where the variance is low $(\sigma=0.01)$, and where it is high $(\sigma=10)$, combined with settings where a change of depreciation method is not allowed (i.e., $p=0$ ), and where a change is accepted with probability $70 \%$ (i.e., $p=0.7$ ). The third column presents the option value in case $p=0.7$, expressed as percentage reduction in the expected present value of tax payments due to the possibility to change depreciation method, i.e., compared to the case where $p=0$.

\begin{tabular}{|c|c||ccc||ccc|}
\hline Scenario & \multicolumn{1}{|c||}{} & \multicolumn{3}{c||}{$\sigma=0.01$} & \multicolumn{3}{c|}{$\sigma=10$} \\
\hline & & SDM & SYD & Opt. value (\%) & SDM & SYD & Opt. value (\%) \\
\hline I & 0 & $\mathbf{1 2 . 8 6}$ & 13.66 & & 38.89 & $\mathbf{3 8 . 8 2}$ & \\
& 0.7 & $\mathbf{1 2 . 6 2}$ & 13.39 & 1.87 & 38.84 & $\mathbf{3 8 . 8 2}$ & 0 \\
\hline II & 0 & 16.05 & $\mathbf{1 5 . 1 2}$ & & 40.81 & $\mathbf{4 0 . 2 7}$ & \\
& 0.7 & 15.30 & $\mathbf{1 5 . 1 2}$ & 0 & 40.44 & $\mathbf{4 0 . 2 7}$ & 0 \\
\hline III & 0 & $\mathbf{1 3 . 5 4}$ & 13.82 & & 38.86 & $\mathbf{3 8 . 5 9}$ & \\
& 0.7 & $\mathbf{1 2 . 7 3}$ & 13.51 & 5.98 & $\mathbf{3 8 . 5 7}$ & 38.59 & 0.05 \\
\hline IV & 0 & 13.77 & $\mathbf{1 3 . 3 9}$ & & 39.01 & $\mathbf{3 8 . 6 6}$ & \\
& 0.7 & 13.33 & $\mathbf{1 2 . 9 2}$ & 3.51 & 38.84 & $\mathbf{3 8 . 6 3}$ & 0.08 \\
\hline
\end{tabular}

As expected, the accelerated method (SYD) is optimal in the scenario with decreasing expected cash flows (scenario II), and the expected present value of tax payments is independent of $p$. The option to change therefore has no value if the initial choice is optimal. However, it does reduce the expected tax payments in case a suboptimal method is chosen initially. This holds for both values of $\sigma$. In contrast, for the scenario with increasing expected cash flows (scenario I), the optimal initial choice depends on the degree of uncertainty in future cash flows. When there is relatively little uncertainty regarding the level of future cash flows $(\sigma=0.01)$, the optimal depreciation scheme is SDM. This occurs because initial cash flows are likely to be low. Therefore, the use of the accelerated method would lead to a too high probability of foregoing tax deduction due to the depreciation charge being higher than the realized cash flow. It is therefore optimal to start with SDM and propose a change to the accelerated method in a later period. So even though there is relatively little uncertainty regarding the level of future cash flows (i.e., $\sigma$ is low), this option can be valuable. In this case, the option to change depreciation method reduces the expected discounted tax payments with 
almost $2 \%$. In contrast, if the variance is high $(\sigma=10)$, the probability that a cash flow exceeds the corresponding depreciation charge is relatively similar for SDM and SYD. Therefore, the optimal choice is SYD in this case. Note that the relatively high level of expected taxable income in case of high variance is due to the fact that taxable income is equal to income if positive.

Finally, with non-monotone patterns in the expected cash flows, i.e., in scenarios III and IV, the option to change yields significant value. This occurs because both the straight line and the accelerated method yield a relatively high probability of a loss in tax deduction due to the fact that the depreciation charge exceeds the cash flow in a certain period. The possibility to change depreciation method allows to reduce this probability. In the case where $\sigma=0.01$, the option reduces expected discounted tax payments by $5.98 \%$ in scenario III, and by $3.51 \%$ in scenario IV.

We now investigate the effect of patterns in the degree of uncertainty in future cash flows, as measured by the variance. Specifically, we let $\mu_{i}=2$ for all $i=1, \ldots, 10$, and define the following two scenarios for $\sigma_{i}$ :

$\mathrm{V}$ : Increasing variance with $\sigma_{i}=0.5 \cdot i-0.5$, and

VI: decreasing variance with $\sigma_{i}=5-0.5 \cdot i$;

VII: decreasing and subsequently increasing variance, with $\left\{\sigma_{1}, \sigma_{2}, \ldots, \sigma_{10}\right\}=\{5,3,1,0.5,0.01,0.01,0.5,1,3,5\}$.

The following table presents the minimum over all possible change strategies of the expected present value of tax payments when the initial method is $S D M$ and $S Y D$, respectively, for the case where $p=0$ and for the case where $p=0.7$. The third column presents the option value expressed as percentage reduction in the expected present value of tax payments due to the possibility to change depreciation method, i.e., compared to the case where $p=0$.

\begin{tabular}{|c|c||ccc|}
\hline Scenario & $p$ & SDM & SYD & Option value (\%) \\
\hline V & 0 & 11.90 & $\mathbf{1 0 . 9 6}$ & \\
& 0.7 & 11.41 & $\mathbf{1 0 . 9 6}$ & 0 \\
\hline VI & 0 & $\mathbf{1 2 . 9 7}$ & 13.16 & \\
& 0.7 & $\mathbf{1 2 . 9 7}$ & 13.00 & 0 \\
\hline VII & 0 & 11.90 & $\mathbf{1 1 . 6 2}$ & \\
& 0.7 & $\mathbf{1 1 . 4 2}$ & 11.56 & 1.72 \\
\hline
\end{tabular}

The option to change depreciation method has no value in scenarios where the variance is constant over time, i.e., scenarios $V$ and $V I$, because it is then not optimal to change depreciation method in a later period. The optimal initial choice is SYD in scenario $\mathrm{V}$, and SDM in scenario VI. High risk in the early years makes SDM optimal. This occurs because the depreciation charge in the first year under the accelerated method is only marginally smaller than the expected cash flow. This implies that when the variance is high, there is a high probability that the firm foregoes some tax deduction. In contrast, in scenario VII the option to change depreciation method has value because the decreasing and increasing pattern in the variances makes it optimal to start with the straight line method and switch to the accelerated method later on. 


\section{Effect of carry forward of losses}

In this section we extend our analysis to allow for carry forward of losses. ${ }^{8}$ It is wellknown that in case carry forward is allowed over the whole depreciable life of the asset, the most accelerated method is always optimal. However, this does not hold when the number of years that losses can be carried forward to compensate profits in later years is limited (see Berg et al. 2001). We first show how the model presented in Sects. 3 and 4 can be extended to include the possibility to carry forward losses. We then present a numerical example that shows that even though the possibility to carry over losses to future periods reduces expected taxable income, the value of the option to change depreciation method can remain significant, and can even increase compared to settings where carry forward of losses is not allowed.

When carry forward of losses is allowed, the optimal decision in a given period is likely to also depend on the amount of loss carry forward that is available to reduce tax payments in future periods. For notational convenience we restrict to the case where losses in period $j$ can only be used to compensate profits in period $j+1$. Let us denote $C F$ for the state variable that indicates the available loss carry forward at the beginning of a period, and let us denote $V_{i}\left(M, D, C F, \bar{\xi}_{i-1}, \bar{\phi}_{i-1}\right)$ for the value function, i.e., the minimal expected present value of future tax payments in periods $i, \ldots, N$, in case method $M$ was used in period $i-1$, the residual tax base equals $D$, the level of carry forward is given by $C F$, and prior proposals and acceptances of changes are given by $\bar{\xi}_{i-1}$, and $\bar{\phi}_{i-1}$, respectively.

Let the state variables $\left(M, D, C F, \bar{\xi}_{i-1}, \bar{\phi}_{i-1}\right)$ be given. In order to determine a recursive relationship for the value function, we denote $f(M, 0,0)$ for the minimal expected present value of tax payments in periods $i, \ldots, N$ in case no change is proposed in period $i, f\left(M^{c}, 1,1\right)$ in case a change is proposed and accepted, and $f(M, 1,0)$ in case a change is proposed, but not accepted. Then, because the amount of loss that can be carried forward to period $i+1$ in case method $M$ is used in period $i$ equals $\left(q_{i, M} \cdot D-C_{i}\right)^{+}$, it follows that the value function in period $i$ is given by:

$$
\begin{aligned}
& V_{i}\left(M, D, C F, \bar{\xi}_{i-1}, \bar{\phi}_{i-1}\right) \\
& \quad=\min \left\{\begin{array}{l}
f(M, 0,0), \\
p_{i}\left(\bar{\xi}_{i-1}, \bar{\phi}_{i-1}\right) \cdot f\left(M^{c}, 1,1\right)+\left(1-p_{i}\left(\bar{\xi}_{i-1}, \bar{\phi}_{i-1}\right)\right) \cdot f(M, 1,0\}
\end{array}\right\},
\end{aligned}
$$

where, for all $s, v \in\{0,1\}$, and $M \in\{A, B\}$,

$$
\begin{aligned}
f(M, s, v)= & \operatorname{Tax}(i, M, D, C F) \\
& +\alpha_{i} \cdot \mathbb{E}\left[V_{i+1}\left(M,\left(1-q_{i, M}\right) D,\left(q_{i, M} D-C_{i}\right)^{+},\left(\bar{\xi}_{i-1}, s\right),\left(\bar{\phi}_{i-1}, v\right)\right],\right.
\end{aligned}
$$

and $\operatorname{Tax}(i, M, D, C F)$ denotes the expected tax payments in period $i$. Because an amount $C F$ of prior losses can be used to compensate profits in period $i$, it follows

\footnotetext{
${ }^{8}$ Several countries allow for alternative loss carryover possibilities like carry backward, i.e., compensating losses with profits in earlier years for tax purposes. We confine our attention to loss carry forward possibilities.
} 


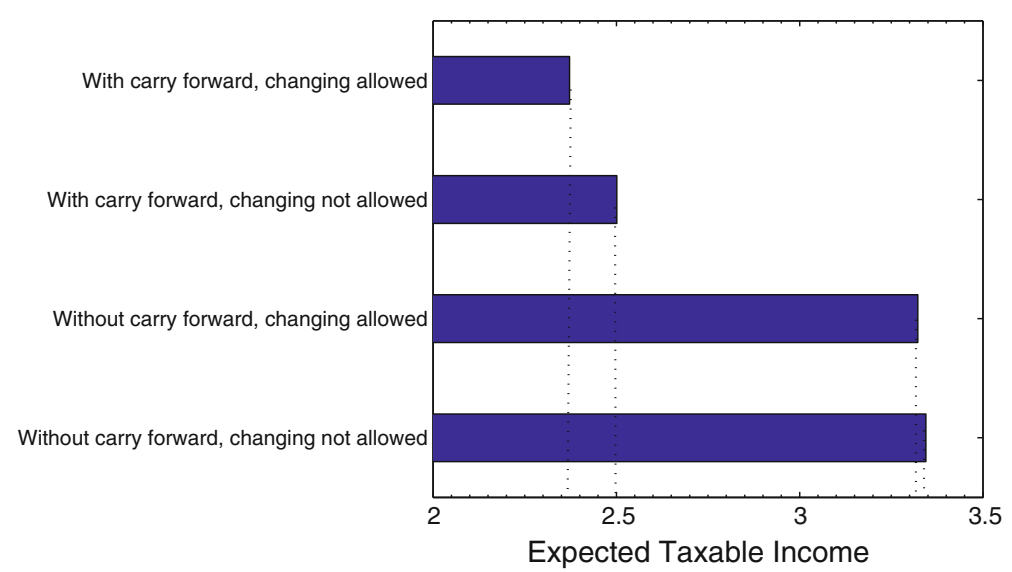

Fig. 3 The effect of carry forward and the option to change the depreciation method

from Lemma 2 that:

$$
\operatorname{Tax}(i, M, D, C F)=\int_{q_{i, M} \cdot D+C F}^{\infty}\left(1-F_{i}(x)\right) \mathrm{d} x
$$

We now illustrate the effect of carry forward on the option to change the depreciation method. Consider an asset with a depreciable lifetime of 5 years $(N=5)$, and an initial value of $D_{0}=5$. Let $\alpha$ be equal to 0.95 . For each period, there are three possible realizations of the cash flows, namely $C_{i}=0,1$, or 3 . The probability distribution of the cash flow in each of the 5 years is given in the following table.

\begin{tabular}{|l|ccccc|}
\hline Prob $\backslash$ Period $i$ & 1 & 2 & 3 & 4 & 5 \\
\hline$P\left(C_{i}=0\right)$ & 0.7 & 0.5 & 0.5 & 0.5 & 0.5 \\
$P\left(C_{i}=1\right)$ & 0.2 & 0.2 & 0 & 0 & 0 \\
$P\left(C_{i}=3\right)$ & 0.1 & 0.3 & 0.5 & 0.5 & 0.5 \\
\hline
\end{tabular}

We compare settings with and without the option to change method, and where either carry forward is not allowed, or losses can be carried forward 1 year. Because expected cash flows are relatively low in earlier years, the preferred initial method is SDM in all four cases. Without carry forward and without the option to change, expected discounted taxable income is 3.34 under SDM and 3.60 under SYD. Allowing one period of carry forward reduces expected discounted taxable income to 2.50 and 2.54 for SDM and SYD, respectively. When a change of method is allowed with certainty, i.e., $p=1$, it is optimal to switch to the more accelerated method SYD during the depreciable lifetime of the asset. This reduces the expected tax payments both in settings with and without carry forward. However, the effect is stronger when carry forward is allowed. This is illustrated in Fig. 3. 
Without carry forward, the option to change depreciation method reduces expected discounted taxable income for the optimal choice (SDM) by $0.6 \%$ (from 3.34 to 3.32). When carry forward is allowed, it reduces the expected discounted taxable income by $5.2 \%$ (from 2.50 to 2.37 ). The intuition for the higher option value in case carry forward is allowed is as follows. It can be verified that whereas when carry forward is not allowed, the option to change is exercised after two periods, it is exercised after one period if carry forward is allowed. This occurs because the depreciation charge in the second period under the accelerated method is high compared to the expected cash flow. Without carry forward, using the accelerated method in the second period leads to a high probability of "loosing" tax deduction when the depreciation charge exceeds the realized cash flow. When carry forward is allowed, however, the risk of "loosing" some of the tax deduction reduces since it can be compensated in the next period. Thus, by changing to the accelerated method earlier, the firm benefits from a higher reduction in tax payments in the second period if cash flow turns out to be high, while the potential loss in case cash flow turns out to be low is less severe than without carry forward because the loss can be used to reduce taxable income in the next period. This is an important benefit because the change to the accelerated method occurs early in the depreciable life, with little discounting and a high tax base of assets.

\section{Conclusion}

The paper extends the literature on optimal tax depreciation by incorporating the option to negotiate a change of depreciation method. It develops a dynamic programming model to determine the firm's optimal strategy with regard to the initial choice of depreciation method, and whether or not to propose changes in later periods. The optimal choice reflects strategic tax planning to lower the expected discounted future tax payments. The model is illustrated by numerical examples. The analysis shows that flexibility of the tax authority with respect to proposed changes creates value for the firm because it can yield significant reductions in the expected present value of tax payments. The value of the option to change depreciation method (in terms of percentage reduction in expected discounted tax payments) depends on the discount factor, the probability that proposed changes are accepted, and whether or not carry forward of losses is allowed. Even though the possibility to carry over losses to future periods reduces expected taxable income, the value of the option to change depreciation method can remain significant. In fact, we find that carry over possibilities can increase the value of the option to change depreciation method compared to settings where carry over of losses is not allowed. This occurs because allowing losses to be carried over may make it optimal to exercise the real option earlier.

Acknowledgments We wish to thank two anonymous reviewers and Dirk Simons for comments that helped to improve the paper significantly.

Open Access This article is distributed under the terms of the Creative Commons Attribution Noncommercial License which permits any noncommercial use, distribution, and reproduction in any medium, provided the original author(s) and source are credited. 


\section{Appendix: Proofs}

Proof of Proposition 1 First, it is clear that it is optimal (never suboptimal) to set $\xi_{i, k}=0$ in all decision nodes in which a change of method was implemented in a predecessor node. Indeed, proposing a change then (i.e., setting $\xi_{i, k}=1$ ) does not affect the probability distribution of the resulting depreciation scheme. Moreover, since changes that are proposed but not accepted do not affect the probability distribution of the resulting depreciation scheme, it is optimal to set $\xi_{i, k}=\xi_{i, 1}$ in every decision node $k$ in which no changes were accepted in prior nodes.

Second, it is seen immediately that the only depreciation schemes that can occur with non-zero probability are $d_{(M, k)}$, for $k=1, \ldots, N$, and $M \in\{A, B\}$.

Now it remains to determine the probability that each of these depreciation schemes will occur, as well as the probability that a change will be proposed in a given period.

- Depreciation scheme $d_{(M, k)}$ for $k<N$ will result if the following three conditions are satisfied:

- a change is proposed at the beginning of period $k+1$, i.e., $\xi_{k+1,1}=1$;

- all prior proposals, if any, were rejected, which occurs with probability $(1-p)^{\sum_{j=2}^{k} \xi_{j, 1}}$; and

- the proposed change in period $k+1$ is accepted, which, given that prior proposals were rejected, occurs with probability $p$.

- Depreciation scheme $d_{(M, N)}$ results if all proposals to change were rejected, which occurs with probability $(1-p)^{\sum_{j=2}^{N} \xi_{j, 1}}$.

This implies that (10) holds true. Next, a change will be proposed in period $i$ iff $\xi_{i, 1}=1$, and all prior proposals, if any, were rejected. Therefore, (11) holds true.

This concludes the proof.

Proof of Lemma 1 Suppose method $f_{M}(\cdot, \cdot)$ is used in periods $j, \ldots, i-1$, and method $M^{c}$ is used in period $j-1$. Then, it follows that

$$
d_{j+k-1}=f_{M}(k, \widetilde{N}) \cdot \widetilde{D}, \quad k=i-j, \ldots, 1,
$$

where $\widetilde{N}=N-j+1$ denotes the remaining depreciable lifetime of the asset at the beginning of period $j$, and $\widetilde{D}$ denotes the residual tax base at the beginning of period $j$. Then, it holds that:

$$
\widetilde{D}=D+\sum_{k=j}^{i-1} d_{k}=D+\sum_{k=1}^{i-j} f_{M}(k, \widetilde{N}) \cdot \widetilde{D}
$$

Therefore, if method $M$ is used in period $i$, the depreciation charge in that period is given by:

$$
\begin{aligned}
d_{i} & =f_{M}(i-j+1, \widetilde{N}) \cdot \widetilde{D} \\
& =q_{i, j, N} \cdot D,
\end{aligned}
$$


where

$$
q_{i, j, N}=\frac{f_{M}(i-j+1, N-j+1)}{1-\sum_{k=1}^{i-j} f_{M}(k, N-j+1)} .
$$

Note that it follows from (2) that

$$
\begin{aligned}
q_{N, \cdot, N} & =\frac{f_{M}(N-j+1, N-j+1)}{1-\sum_{k=1}^{N-j} f_{M}(k, N-j+1)} \\
& =1 .
\end{aligned}
$$

This concludes the proof.

Proof of Lemma 2 Follows immediately from Lemma 1, and the fact that for any given random variable $X$ with cumulative distribution function $F(\cdot)$, and any $d \in \mathbb{R}$, it holds that

$$
E\left[(X-d)^{+}\right]=\int_{d}^{\infty}(1-F(x)) \mathrm{d} x .
$$

Proof of Proposition 2 At any given period $i=2, \ldots, N$, the firm decides whether or not to propose a switch of depreciation method, i.e., whether to stick with method $M$ (i.e., $\xi_{i}=0$ ) or to propose a switch to method $M^{c}$ (i.e., $\xi_{i}=1$ ). For both options, the present value of future tax payments is given by the sum of expected value of tax payments in period $i$, and the expected present value of future tax payments in periods $i+1, \ldots, N$.

- If $\xi_{i}=0$, then method $M$ is used in period $i$, so that the expected tax payments in period $i$ are given by $\operatorname{Tax}(i, M, D)$, and the residual tax base in period $i+1$ is given by $\left(1-q_{i, M}\right) D$. Because no change was proposed this implies that the value function in period $i+1$ is given by $V_{i+1}\left(M,\left(1-q_{i, M}\right) D,\left(\bar{\xi}_{i-1}, 0\right),\left(\bar{\phi}_{i-1}, 0\right)\right)$.

- If $\xi_{i}=1$, with probability $p_{i}\left(\bar{\xi}_{i-1}, \bar{\phi}_{i-1}\right)$, the proposal will be accepted, so that the expected tax payments in period $i$ are given by $\operatorname{Tax}\left(i, M^{c}, D\right)$, and the residual tax base in period $i+1$ is given by $\left(1-q_{i, M^{c}}\right) D$. Because a change was proposed and accepted, the value function in period $i+1$ is given by $V_{i+1}\left(M^{c},\left(1-q_{i, M^{c}}\right) D,\left(\bar{\xi}_{i-1}, 1\right),\left(\bar{\phi}_{i-1}, 1\right)\right)$. With probability $1-p_{i}\left(\bar{\xi}_{i-1}, \bar{\phi}_{i-1}\right)$, the proposal is not accepted, so that the expected tax payments in period $i$ are given by $\operatorname{Tax}(i, M, D)$, and the residual tax base in period $i+1$ is given by $\left(1-q_{i, M}\right) D$. Because a change was proposed but not accepted, the value function in period $i+1$ is given by $V_{i+1}\left(M,\left(1-q_{i, M}\right) D,\left(\bar{\xi}_{i-1}, 1\right),\left(\bar{\phi}_{i-1}, 0\right)\right)$.

In period $i=1$, both methods are accepted with probability 1 , and there is no proposal to change, so that the expected tax to be paid in period 1 is given by $\operatorname{Tax}\left(1, M, D_{0}\right)$, and the value function at date 2 is given by $V_{2}\left(M,\left(1-q_{1, M}\right) D_{0}\right)$.

Proof of Proposition 3 Let $i \in\{1, \ldots, N-1\}, M \in\{A, B\}, D \in\left[0, D_{0}\right], \bar{\xi}_{i-1} \in$ $\{0,1\}^{i-2}$, and $\bar{\phi}_{i-1} \in\{0,1\}^{i-2}$ be given, and denote $G_{i}\left(\alpha_{i}\right)$ for the expected benefit 
of proposing a change in period $i$, given the current method $M$, the residual tax base $D$, and $\bar{\xi}_{i-1}, \bar{\phi}_{i-1}$. It then follows from Proposition 2 that:

$$
\begin{aligned}
G_{i}\left(\alpha_{i}\right)= & p_{i}\left(\bar{\xi}_{i-1}, \bar{\phi}_{i-1}\right) \cdot\left[\operatorname{Tax}(i, M, D)-\operatorname{Tax}\left(i, M^{c}, D\right)\right] \\
& +\alpha_{i} \cdot S_{i+1}\left(M, D, \bar{\xi}_{i-1}, \bar{\phi}_{i-1}\right),
\end{aligned}
$$

where $S_{i+1}\left(M, D, \bar{\xi}_{i-1}, \bar{\phi}_{i-1}\right)$ is as defined in (16). It is optimal to propose a change in period $i$ iff $G_{i}\left(\alpha_{i}\right)>0$. Note that $G_{i}\left(\alpha_{i}\right)$ is linear in $\alpha_{i}$, and

$$
G_{i}(0)=p_{i}\left(\bar{\xi}_{i-1}, \bar{\phi}_{i-1}\right) \cdot\left[\operatorname{Tax}(i, M, D)-\operatorname{Tax}\left(i, M^{c}, D\right)\right]
$$

We now show that i) and ii) are satisfied with $\widetilde{\alpha}_{i} \in[0,1]$ defined as follows:

$$
\begin{aligned}
\widetilde{\alpha}_{i} & =1, & & \text { if } \nexists \alpha \in[0,1] \text { s.t. } G_{i}(\alpha)=0, \\
& =G_{i}^{-1}(0), & & \text { otherwise. }
\end{aligned}
$$

We distinguish the following two cases:

- If the current method $M$ is the most accelerated method, i.e., $q_{i, M}>q_{i, M^{c}}$, then $G_{i}(0)=p_{i} \int_{q_{i, M} D}^{q_{i, M^{c}} D}\left(1-F_{i}(x)\right) \mathrm{d} x \leq 0$. Therefore,

- If $\widetilde{\alpha}_{i}=1$, then $G_{i}(\alpha) \leq 0$ for all $\alpha \in[0,1]$.

- If $\widetilde{\alpha}_{i}<1$, then $G_{i}(\alpha)<0$ for all $\alpha<\widetilde{\alpha}_{i}$ and $G_{i}(\alpha)>0$ for all $\alpha>\widetilde{\alpha}_{i}$.

Since $q_{i, M}>q_{i, M^{c}}$, this implies that the most (least) accelerated method is preferable for $\alpha<\widetilde{\alpha}_{i}\left(\alpha>\widetilde{\alpha}_{i}\right)$.

- If the current method $M$ is the least accelerated method, i.e., $q_{i, M}<q_{i, M^{c}}$, then $G_{i}(0)>0$. Therefore,

- If $\widetilde{\alpha}_{i}=1$, then $G_{i}(\alpha) \geq 0$ for all $\alpha \in[0,1]$.

- If $\widetilde{\alpha}_{i}<1$, then $G_{i}(\alpha)>0$ for all $\alpha<\widetilde{\alpha}_{i}$ and $G_{i}(\alpha)<0$ for all $\alpha>\widetilde{\alpha}_{i}$.

Since $q_{i, M}<q_{i, M^{c}}$, this implies that the most (least) accelerated method is preferable for $\alpha<\widetilde{\alpha}_{i}\left(\alpha>\widetilde{\alpha}_{i}\right)$.

This concludes the proof.

\section{References}

Arkin VI, Slastnikov AD (2007) The effect of depreciation allowances on the timing of investment and government tax revenue. Ann Oper Res 151:307-323

Berg M, De Waegenaere A, Wielhouwer JL (2001) Optimal tax depreciation with uncertain future cashflows. Eur J Oper Res 132(1):185-197

Berg M, Moore G (1989) The choice of depreciation methods under uncertainty. Decis Sci 20:643-654

Davidson S, Drake D (1961) Capital budgeting and the 'best' tax depreciation method. J Bus 34:442-452

Davidson S, Drake D (1964) The 'best' tax depreciation method. J Bus 37:258-260

De Waegenaere A, Wielhouwer JL (2002) Optimal tax depreciation lives and charges under regulatory constraints. OR Spectr 24:151-177

De Waegenaere A, Sansing RC, Wielhouwer JL (2003) Valuation of a firm with a tax loss carryover. J Am Tax Assoc 25(supplement):65-82

Dedner M, Gunther R, Runger R (1980) Ertragsteuerplanung bei unvollkommener Information. Z Oper Res 24:239-257

Kromschroder B (1984) Zum Einfluss der Unsicherheit auf die steuerliche Abschreibungspolitik der Unternehmung. Z betriebswirtsch Forsch, 1014 
Kunkel P (1992) Steuerbilanzpolitik unter Unsicherheit. Steuer und Wirtsch, pp 59-65

Roemmich R, Duke GL, Gates WH (1978) Maximizing the present value of tax savings from depreciation. Manag Acc 56:55-57

Rueckle D (1983) Normative Theorie der Steuerbilanzpolitik. Wien

Sansing R (1998) Valuing the deferred tax liability. J Acc Res 36:357-363

U.S. Department of the Treasury (2008) How to depreciate property. Internal Revenue Service Publication 946. U.S. Government Printing Office, Washington, DC

Wakeman LM (1980) Optimal tax depreciation. J Acc Econ 1:213-237

Wielhouwer JL, De Waegenaere A, Kort PM (2000) Optimal dynamic investment policy for different tax depreciation rates and economic depreciation rates. J Optim Theory Appl 106(1):23-48

Wielhouwer JL, De Waegenaere A, Kort PM (2002) Optimal tax depreciation under a progressive tax system. J Econ Dyn Control 27:243-269 